$07.2 ; 13.3$

\title{
Зависимость электрической проводимости никель-саленовых полимеров от напряжения затвор-исток в электрохимическом транзисторе
}

\author{
(C) Е.А. Смирнова, И.А. Чепурная \\ Физико-технический институт им. А.Ф. Иофффе РАН, Санкт-Петербург, Россия \\ `E-mail: ichepurnaya@mail.ioffe.ru
}

Поступило в Редакцию 19 августа 2021 г.

В окончательной редакции 19 августа 2021 г.

Принято к публикации 14 сентября 2021 г.

Полимерные формы комплексов N,N'-бис(салицилиден)этилендиаминоникель (II) и N,N'-бис(3-метоксисалицилиден)этилендиаминоникель (II) впервые исследованы в качестве функциональных материалов для проводящих каналов органических электрохимических транзисторов. Установлена зависимость электропроводности полимеров от уровня легирования анионами фонового электролита. Показано, что параметры кривых зависимости проводимости полимерных пленок от напряжения на затворе определяются молекулярной структурой комплекса и природой электролитного растворителя.

Ключевые слова: органическая электроника, электрохимический транзистор, никель-саленовый полимер, проводимость, легирование.

DOI: 10.21883/PJTF.2022.01.51871.18998

Среди различных молекулярных электронных устройств, использующих покрытия на основе полимерных полупроводников, особый интерес вызывают органические электрохимические транзисторы (ОЭХТ) [1-3]. В отличие от широко известных органических полевых транзисторов в ОЭХТ затвор электрически связан с проводящим каналом на основе полимерного полупроводника через электролитную систему. Функционирование ОЭХТ основано на инжекции ионов электролита в объем канала при подаче на затвор управляющего напряжения. Проводимость канала при этом определяется концентрацией и подвижностью носителей заряда, возникающих в полимере в результате окислительно-восстановительных превращений.

В качестве перспективных материалов для каналов ОЭХТ предложены как электропроводные органические полимеры (например, полиэтилендиокситиофен, допированный полистиролсульфонатом) [3], так и проводящие полимерные материалы на основе металлоорганических и координационных соединений [4]. Интересными представителями металлополимеров с собственной проводимостью являются никель-саленовые полимеры (полимерные комплексы никеля (II) с $\mathrm{N}_{2} \mathrm{O}_{2}$ основаниями Шиффа саленового типа), представляющие собой иммобилизованные на токопроводящих подложках тонкопленочные матрицы, в которых цепочечные макромолекулы с ковалентно связанными арильными фрагментами (рис. $1, a$ ) объединены в трехмерные супрамолекулярные структуры [5]. Простота модульного синтеза, хорошая устойчивость и возможность достижения высокого уровня электрофизических и электрохимических характеристик обеспечивают широкий диапазон областей практического использования данных полимерных металло- комплексов, в частности, в устройствах генерации и накопления энергии, сенсорных и электрокаталитических ячейках [6]. Ранее было установлено, что варьирование потенциала электрода-подложки обеспечивает переход материала из незаряженного в окисленное состояние. Образующийся в полимерной пленке избыточный положительный заряд стабилизируется за счет легирования (допирования) анионами фонового электролита (рис. 1, a) [5]. Таким образом, никель-саленовые полимеры потенциально могут обеспечить функционирование ОЭХТ в режиме обогащения канала носителями заряда.

Для более точной оценки возможности использования никель-саленовых полимеров в ОЭХТ необходимо установить закономерности влияния факторов молекулярной и структурной (надмолекулярной) организации полимерной матрицы и состава электролитной среды на изменение электропроводности материала при электрохимическом легировании. Электрическая проводимость отдельных представителей этих полимерных металлокомплексов была ранее исследована в работе [7], однако эксперименты проводились в электролитной композиции для литий-ионного аккумулятора, содержащей высокую концентрацию ионов лития, способных к специфической координации к гетероатомам лиганда. Подобные взаимодействия существенно влияют на распределение электронной плотности в полимере, определяющее особенности генерации и транспорта носителей заряда в нем [8]. Целью настоящей работы является исследование влияния молекулярного состава полимера и природы электролитного растворителя на проводимость никельсаленовых полимерных пленок при электрохимическом легировании в растворах, не содержащих ионов лития. 

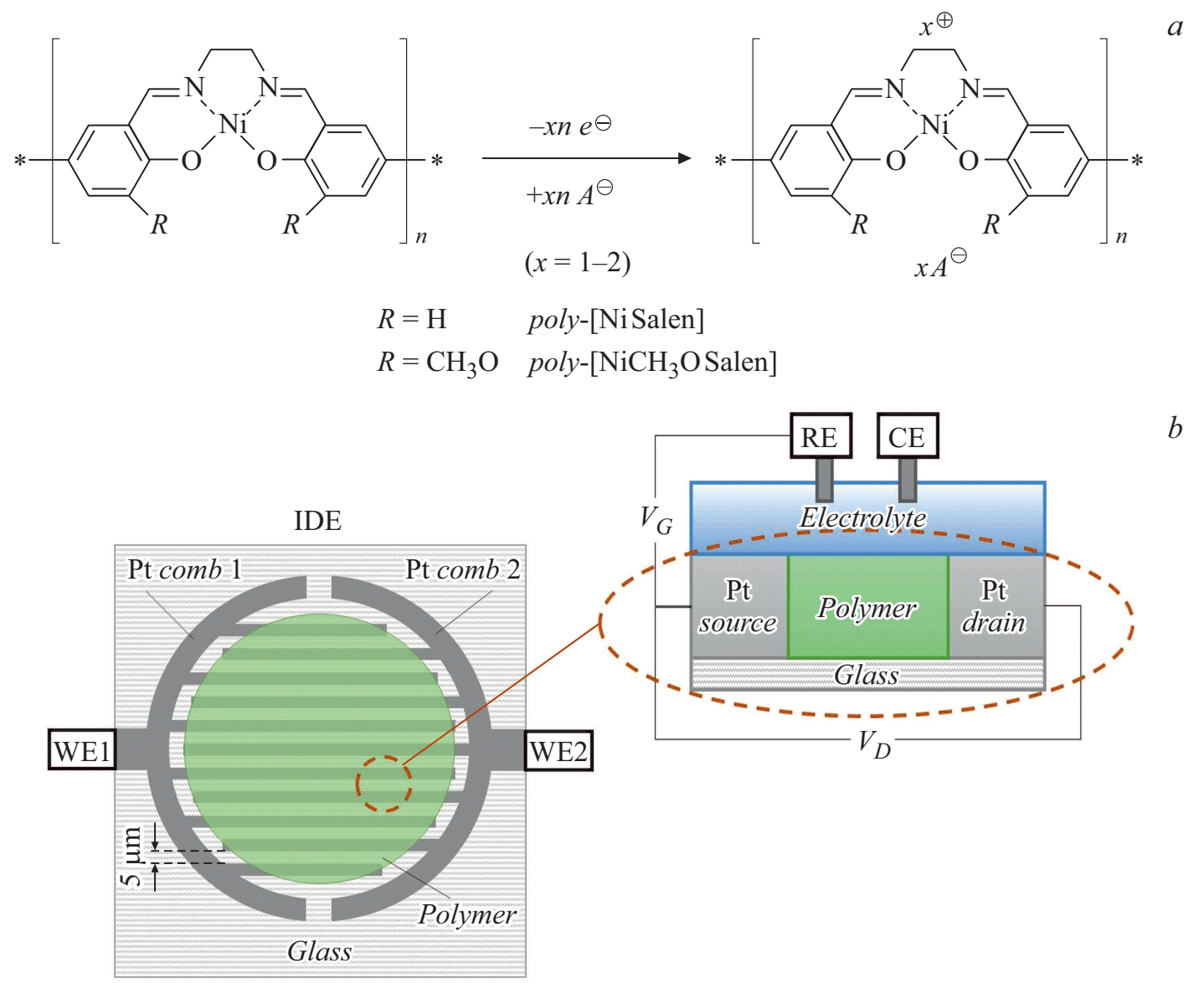

Рис. 1. $a-$ структурная формула макромолекул никель-саленовых полимеров, общая схема их электрохимического легирования анионами фонового электролита и условные обозначения полимеров, исследованных в работе. $b-$ схема полимермодифицированного гребенчатого электрода и электрохимического транзистора на его основе.

Полимерные пленки, poly-[NiSalen] и poly[NiCH${ }_{3}$ OSalen] (рис. 1, $a$ ), были получены на поверхности платинового гребенчатого электрода (ГЭ) (MicruX Technologies) (рис. 1, $b$ ) методом окислительной электрополимеризации комплексов $\mathrm{N}, \mathrm{N}^{\prime}$-бис (салицилиден)этилендиаминатоникель (II) и N, $\mathrm{N}^{\prime}$-бис (3-метоксисалицилиден)этилендиаминатоникель (II) соответственно. Две встречно направленные системы микроэлектродов (гребенки) ГЭ, нанесенные на стеклянную подложку, являлись рабочими электродами (WE1 и WE2) электрохимической ячейки, управляемой c помощью бипотенциостата VSP (BioLogic Science Instruments). Ячейка также содержала стеклоуглеродную пластину в качестве вспомогательного электрода (CE) и неводный электрод сравнения $\mathrm{Ag} / \mathrm{Ag}^{+}$(MW-1085, $\mathrm{BASi}$ (RE), характеризующийся потенциалом $-0.3 \mathrm{~V}$ по отношению к стандартному хлоридсеребряному электроду $\mathrm{Ag} / \mathrm{AgCl}, \mathrm{NaCl}$ (насыщ.), относительно которого приводятся все значения электродных потенциалов в настоящей работе. Ячейка заполнялась электролитной композицией, содержащей $0.05 \mathrm{~mol} \cdot 1^{-1}$ тетрафторобората тетраэтиламмония $\left(\mathrm{Et}_{4} \mathrm{NBF}_{4}\right)$ и растворитель (1,2-дихлороэтан (ДХЭ) или ацетонитрил
$(\mathrm{AH})), \quad$ а также $0.001 \mathrm{~mol} \cdot 1^{-1}$ мономера [NiSalen] или $\left[\mathrm{NiCH}_{3} \mathrm{OSalen}\right]$, синтезированного по стандартной методике [9]. Комплекс полимеризовался на поверхности ГЭ в режиме многократного циклирования потенциала в диапазоне от 0 до $1.6 \mathrm{~V}$ со скоростью $10 \mathrm{mV} \cdot \mathrm{s}^{-1}$ (процедура синтеза полимера подробно представлена в работе [7]). Полимермодифицированный электрод промывался, высушивался и помещался в ячейку с электролитной композицией, идентичной по составу раствору для полимеризации, но не содержащей мономер.

Два соседних встречно направленных микроэлектрода ГЭ, соединенных никель-саленовым полимером, можно рассматривать как электрохимический транзистор с полимерным каналом (рис. 1,b). Затвор образован комбинацией вспомогательного электрода и электрода сравнения в растворе электролита. Управляющее напряжение затвор-исток $\left(V_{G}\right)$ эквивалентно заданной разности потенциалов в цепи рабочего электрода и электрода сравнения. С помощью бипотенциостата производилось увеличение $V_{G}$ от 0 до $1.6 \mathrm{~V}$ со скоростью $10 \mathrm{mV} \cdot \mathrm{s}^{-1}$. Между двумя гребенками ГЭ поддерживалась постоянная разность потенциалов $V_{D}=10 \mathrm{mV}$, обеспечивающая протекание тока стока в полимерном канале. Измерялся 

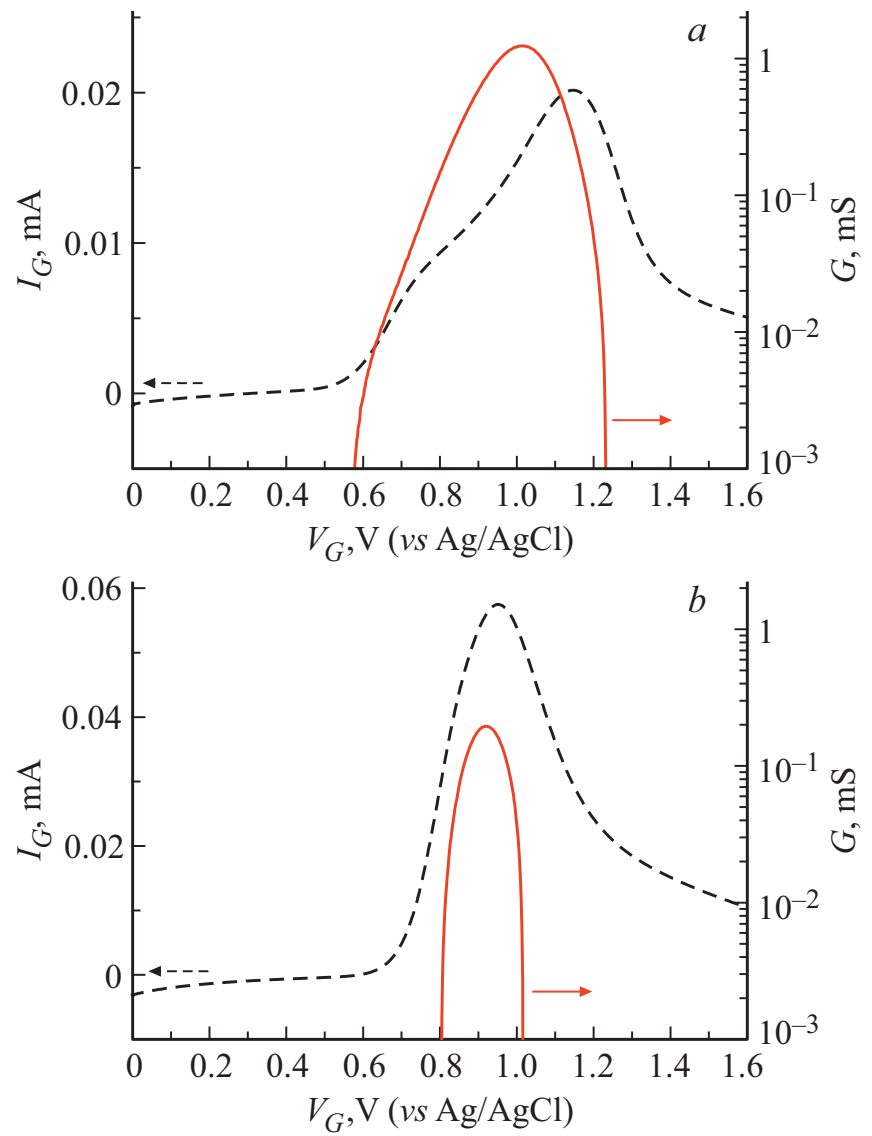

Рис. 2. Зависимость тока затвора $I_{G}$ (штриховая линия) и проводимости $G$ (сплошная линия) от напряжения затвор-исток $V_{G}$ для ОЭХТ с полимерным каналом poly-[NiSalen] в электролите на основе 1,2-дихлороэтана $(a)$ и ацетонитрила $(b)$.

электрический ток в цепи рабочего и вспомогательного электродов $\left(I_{G}\right)$ для WE1 и WE2, и по разности полученных значений $\left(\Delta I_{G}\right)$ рассчитывалась проводимость полимера $(G)$ с помощью формулы [7]:

$$
G=\frac{\Delta I_{G}}{2 V_{D}} .
$$

Экспериментально полученные зависимости $I_{G}=f\left(V_{G}\right)$ и $G=f\left(V_{G}\right)$ для poly-[NiSalen] представлены на рис. 2 , а для poly-[ $\mathrm{NiCH}_{3}$ OSalen] - на рис. 3. Во всех исследованных случаях полимеры являются непроводящими $\left(G<10^{-3} \mathrm{mS}\right)$ в незаряженном состоянии (при $\left.V_{G}=0 \mathrm{~V}\right)$. При смещении $V_{G}$ выше порогового значения регистрируются различные значения токов $I_{G}$, свидетельствующие о протекании окислительных процессов в никель-саленовом полимерном канале. С увеличением уровня электрохимического легирования проводимость полимеров резко возрастает, достигает максимальных значений и далее уменьшается. Полученные кривые $G=f\left(V_{G}\right)$ с одним (для poly-[NiSalen]) или двумя (для poly-[ $\left.\left.\mathrm{NiCH}_{3} \mathrm{OSalen}\right]\right)$ максимумами значительно отличаются от сигмоидальных кривых зависимости проводимости от напряжения, характерных для сопряженных органических полимерных пленок. Напротив, они сходны с кривыми $G=f\left(V_{G}\right)$, регистрируемыми для редоксполимеров или проводящих матриц с локальными областями сопряжения, перенос заряда между которыми осуществляется по прыжковому механизму [10]. Ранее было установлено, что окисление системы фенильных колец лигандов никель-саленовых полимеров приводит к последовательному появлению двух типов носителей заряда в пленке: катион-радикалов и дикатионов [5]. Можно предположить, что для полимера poly-[ $\left.\mathrm{NiCH}_{3} \mathrm{OSalen}\right]$ максимумы на кривых $G=f\left(V_{G}\right)$ наблюдаются при достижении одинаковых концентраций частиц в смешанновалентных системах нейтральный фрагмент/катионрадикал и катион-радикал/дикатион соответственно. В случаe poly-[NiSalen] процесс образования дикатионов затруднен [5], поэтому на соответствующих кривых наблюдается лишь один максимум проводимости.

Пороговое напряжение затвор-исток существенно меньше для poly-[ $\mathrm{NiCH}_{3}$ OSalen], чем для poly-[NiSalen], что, очевидно, связано с большей легкостью окисления макромолекул с электронодонорными $\mathrm{CH}_{3} \mathrm{O}$-группами в структуре лиганда. Переход из непроводящего в проводящее состояние сопровождается увеличением значений
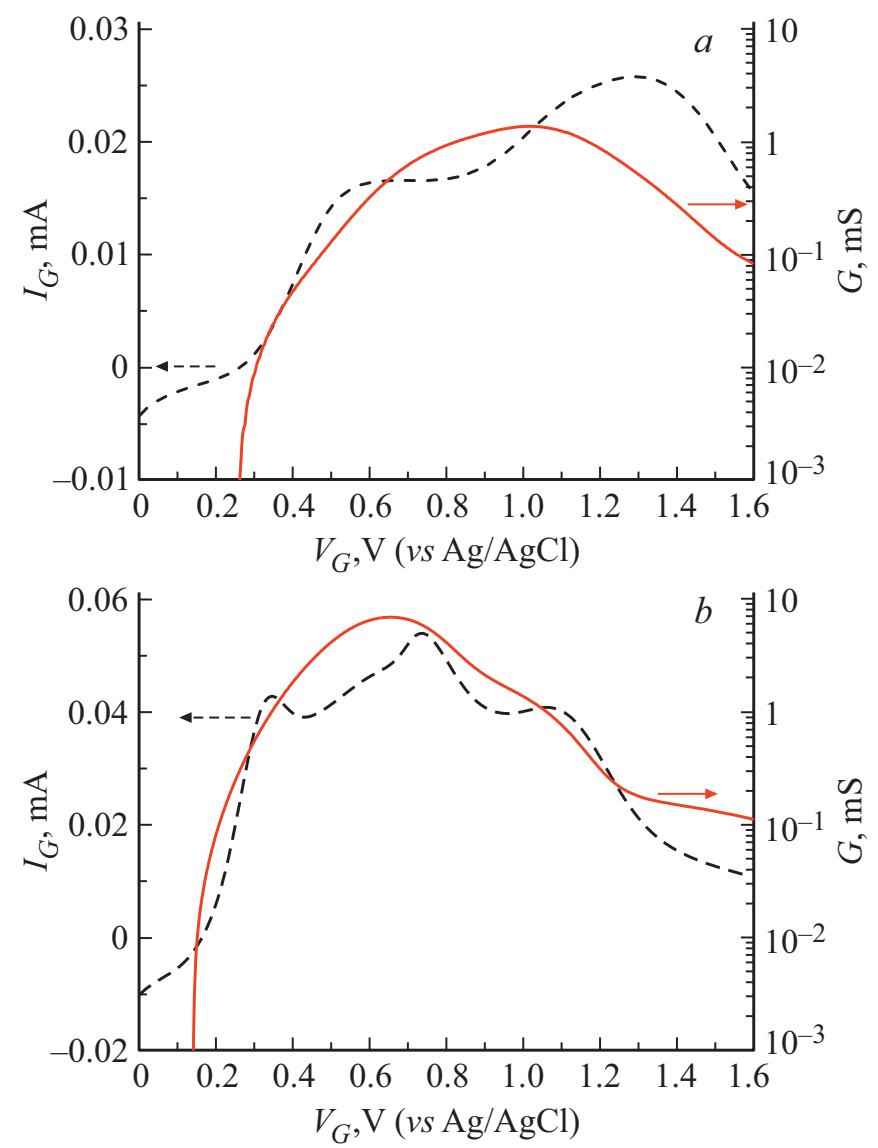

Рис. 3. Зависимость тока затвора $I_{G}$ (штриховая линия) и проводимости $G$ (сплошная линия) от напряжения затвор-исток $V_{G}$ для ОЭХТ с полимерным каналом poly-[ $\left.\mathrm{NiCH}_{3} \mathrm{OSalen}\right]$ в электролите на основе 1,2-дихлороэтана $(a)$ и ацетонитрила $(b)$. 
$G$ на два-три порядка величины в случае poly-[NiSalen] и на три-четыре порядка в случае poly-[ $\left.\mathrm{NiCH}_{3} \mathrm{OSalen}\right]$ в зависимости от типа растворителя. Для обоих полимеров при переходе от АН к ДХЭ наблюдается смещение основного максимума проводимости в область более высоких значений $V_{G}$. Проводимость poly-[NiSalen] после достижения максимума быстро уменьшается до $G<10^{-3} \mathrm{mS}$. Значения $G$ для сильно легированной полимерной пленки poly-[ $\left.\mathrm{NiCH}_{3} \mathrm{OSalen}\right]$ уменьшаются по сравнению с максимальными (на два порядка величины в АН и на один порядок в ДХЭ), но остаются на уровне $10^{-1} \mathrm{mS}$ при $V_{G}=1.3 \mathrm{~V}$. Таким образом, диапазон напряжений, соответствующих электропроводящему состоянию пленки poly-[ $\left.\mathrm{NiCH}_{3} \mathrm{OSalen}\right]$ (окно проводимости), варьируется от 1.35 до $1.45 \mathrm{~V}$ (в электролитных системах на основе ДХЭ и АН соответственно). В случае полимера poly-[NiSalen] ширина окна проводимости уступает значениям, полученным для poly[NiCH${ }_{3}$ OSalen], и более существенно зависит от природы растворителя, составляя $0.6 \mathrm{~V}$ в электролите на основе 1,2-дихлороэтана и $0.2 \mathrm{~V}$ в ацетонитрильном растворе.

Наблюдаемые изменения параметров кривых $G=f\left(V_{G}\right)$ при переходе от 1,2-дихлороэтана к ацетонитрилу могут быть связаны с различиями в их донорной способности (значения донорных чисел равны 0.0 для ДХЭ и 14.1 для АН) и диэлектрической проницаемости (значения диэлектрических постоянных равны 10.36 для ДХЭ и 38.0 для АН). Данные характеристики электролитных растворителей, использующихся для синтеза и последующего электрохимического легирования никельсаленовых полимеров, могут оказывать существенное влияние на факторы, определяющие концентрацию $(n)$ и подвижность $(\mu)$ носителей заряда в пленках, а следовательно, и их электропроводность $(G \propto n \mu)$. К таким факторам, в частности, относятся: 1) длина цепи макромолекул и межцепные расстояния в полимерной матрице; 2) зарядовое состояние металлических центров в сильно легированных полимерах; 3) внутрицепные и межмолекулярные электростатические взаимодействия в пленках при различных уровнях легирования. Влияние природы растворителя на указанные выше факторы может быть разнохарактерным для полимеров с различной электронной структурой лигандов. Этим, по-видимому, объясняется отсутствие единых закономерностей изменения параметров кривых $G=f\left(V_{G}\right)$ для полимеров poly-[NiSalen] и poly-[ $\left.\mathrm{NiCH}_{3} \mathrm{OSalen}\right]$ при варьировании электролитного растворителя.

Таким образом, в работе показана возможность управления параметрами зависимости электрической проводимости никель-саленовых полимеров от напряжения затвора путем варьирования молекулярного состава полимерной пленки и природы растворителя электролитной системы. Установлено, что пленка poly-[ $\mathrm{NiCH}_{3}$ OSalen] в ацетонитрильном растворе характеризуется широким окном электрической проводимости и может переходить в проводящее состояние при низком значении порогового напряжения, при этом электропроводность изменяется в пределах четырех порядков величины. Это позволяет предварительно отнести данный полимер к перспективным материалам для каналов органических электрохимических транзисторов.

\section{Конфликт интересов}

Авторы заявляют, что у них нет конфликта интересов.

\section{Список литературы}

[1] P.R. Paudel, J. Tropp, V. Kaphle, J.D. Azoulay, B. Lüssem, J. Mater. Chem. C, 9 (31), 9761 (2021). DOI: 10.1039/D1TC01601F

[2] D. Tu, S. Fabiano, Appl. Phys. Lett., 117 (8), 080501 (2020). DOI: $10.1063 / 5.0012599$

[3] E. Zeglio, O. Inganäs, Adv. Mater., 30 (44), 1800941 (2018). DOI: $10.1002 /$ adma.201800941

[4] M.T. Nguyen, R.A. Jones, B.J. Holliday, Coord. Chem. Rev., 377, 237 (2018). DOI: 10.1016/j.ccr.2018.08.004

[5] I.A. Chepurnaya, M.P. Karushev, E.V. Alekseeva, D.A. Lukyanov, O.V. Levin, Pure Appl. Chem., 92 (8), 1239 (2020). DOI: 10.1515/pac-2019-1218

[6] C. Freire, M. Nunes, C. Pereira, D.M. Fernandes, A.F. Peixoto, M. Rocha, Coord. Chem. Rev., 394, 104 (2019). DOI: 10.1016/j.ccr.2019.05.014

[7] Е.В. Белецкий, Ю.А. Волосатова, С.Н. Елисеева, О.В. Левин, Электрохимия, 55 (4), 500 (2019). DOI: $10.1134 / \mathrm{S} 0424857019030034$

[8] I. Kiersztyn, L. Neto, A. Carneiro, J. Tedim, C. Freire, A.R. Hillman, J. Solid State Electrochem., 16 (9), 2849 (2012). DOI: 10.1007/s10008-012-1698-3

[9] P. Pfeiffer, E. Breith, E. Liibbe, T. Tsumaki, Justus Liebigs Ann. Chem., 503 (1), 84 (1933). DOI: $10.1002 /$ jlac. 19335030106

[10] G. Salinas, B.A. Frontana-Uribe, ChemElectroChem., 6 (16), 4105 (2019). DOI: 10.1002/celc.201801488. 